\title{
Pulmonary hypertension: the importance of a multidisciplinary approach
}

\author{
M. C. Post ${ }^{1}$ E. E. van der Wall ${ }^{2}$
}

Published online: 17 May 2016

(c) The Author(s) 2016. This article is available at SpringerLink with Open Access

In this special issue of the Netherlands Heart Journal different aspects of pulmonary hypertension are elucidated.

Pulmonary hypertension $(\mathrm{PH})$ is a haemodynamic state defined as a mean pulmonary artery pressure of $\geq 25 \mathrm{mmHg}$ assessed by right heart catheterisation at rest [1]. Furthermore, PH can be divided into two main haemodynamic profiles: a pre-capillary (with a pulmonary artery wedge pressure (PAWP) $\leq 15 \mathrm{mmHg}$ ) and post-capillary form (with a PAWP $>15 \mathrm{mmHg}$ ).

Subsequently, $\mathrm{PH}$ can be found in different clinical conditions and is categorised into five groups based on a similar presentation, haemodynamic profile, pathological findings, and treatment: pulmonary arterial hypertension $(\mathrm{PAH})$ (group 1), PH based on left heart disease (group 2), $\mathrm{PH}$ due to lung disease and/or hypoxaemia (group 3), chronic thromboembolic PH (CTEPH) (group 4), and PH with unclear and/or multifactorial mechanisms (group 5) [1, 2]. Patients with congenital heart disease (CHD) with a prevalent or corrected systemic-to-pulmonary shunt are at risk for the development of PAH [3]. One of the best examples of a disease associated with $\mathrm{PH}$ based on a multifactorial aetiology (group 5) is sarcoidosis, a rare multisystemic disorder characterised by non-caseating granulomas that can present in multiple tissues. Both pre- and post-capillary forms of PH might be found. In a review by Huitema et al. different aspects of $\mathrm{PH}$ in pulmonary sarcoidosis are de-

M. C. Post

m.post@antoniusziekenhuis.nl

1 Department of Cardiology, St. Antonius Hospital, Nieuwegein, The Netherlands

2 Netherlands Society of Cardiology/Holland Heart House, Utrecht, The Netherlands scribed, underlying the importance of a multidisciplinary approach [4].

The prevalence of $\mathrm{PH}$ varies between each group; leftsided heart disease is the most common cause of PH. Up to $70 \%$ of patients with severe chronic heart failure suffered from $\mathrm{PH}$ [5], whereas the prevalence of pulmonary arterial hypertension $(\mathrm{PAH})$ is estimated to be between 15 and 60 patients per million population [6]. The estimated prevalence of $\mathrm{PAH}$ in $\mathrm{CHD}$ is about $10 \%$, depending on the underlying defect and other characteristics [7]. In all subgroups of $\mathrm{PH}$, quality of life $(\mathrm{QoL})$ is decreased and mortality substantially increased compared with patients without PH. The most important predictors for survival are: functional class or exercise capacity, QoL, performance of the right ventricle and different pulmonary haemodynamic measurements found by right heart catheterisation [1]. The diagnosis of PAH has a tremendous psychosocial impact on patients and their families, and is associated with a high prevalence of anxiety and depression, in up to $40 \%$ with an impairment of QoL $[8,9]$.

Wapenaar et al. describe the validation of the diseasespecific Cambridge Pulmonary Hypertension Outcome Review (CAMPHOR) for the Dutch population [10]. Different standard generic questionnaires for heart and lung diseases have been used to report QoL in PH. However, the CAMPHOR seems to be superior to the standard questionnaires in the assessment of PH-related outcome [11]. Therefore, it is important to use the Dutch version of this questionnaire to have a valid and reliable measure of the QoL in patients with $\mathrm{PH}$.

Transthoracic echocardiography is mandatory as firstline screening tool in patients at risk for the development of $\mathrm{PH}$ or if the presence of $\mathrm{PH}$ is clinically suspected. Based on the peak tricuspid regurgitation velocity (TRV) and the presence of additional findings (including measurements of 
the right and left ventricle, pulmonary artery and inferior vena cava or right atrium), the echocardiographic probability of $\mathrm{PH}$ is divided into low (TRV $<2.8 \mathrm{~m} / \mathrm{s}$ without additional findings), intermediate or high (TRV 2.9 to $3.4 \mathrm{~m} / \mathrm{s}$ with additional findings or $>3.4 \mathrm{~m} / \mathrm{s}$ ) [1]. Furthermore, echocardiography can be helpful in detecting the cause of $\mathrm{PH}$, mainly associated with left and/or congenital heart disease and seems to predict outcome.

In a review article by Baggen et al., the association between different echocardiographic parameters and outcome, defined as mortality or lung transplantation, was investigated in a meta-analysis [12]. They found that the presence of pericardial fluid, right atrial enlargement, and a decrease in the tricuspid annular plane systolic excursion are the best predictors for worse outcome.

Based on the echocardiographic probability of PH further diagnostic evaluation should be performed to identify the aetiology of $\mathrm{PH}$, including pulmonary function tests, chest $\mathrm{CT}$ and ventilation/perfusion scintigraphy to exclude lung disease and pulmonary embolism [1, 13]. If PAH or CTEPH is suspected the patient should be referred to an expert centre to confirm the diagnosis by specific diagnostic tests, including right heart catheterisation. Goal-oriented targeted PH-specific therapy is indicated in symptomatic patients (functional class $\geq 2$ ) with pulmonary vascular disease, besides general and supportive therapy [1]. The response to this specific medication should be evaluated every 3 to 6 months based on symptoms, functional class, exercise capacity, biomarkers, imaging and sometimes haemodynamics.

Van Riel et al. evaluate the differences in clinical presentation and outcome after the initiation of $\mathrm{PH}$-specific therapy in patients with CHD in the Netherlands versus Singapore [14]. They and others found that the time of clinical presentation, effect and type of initial treatment is influenced by differences in socioeconomic status and healthcare systems $[14,15]$.

If the clinical response is inadequate sequential double or triple therapy should be given, and maybe other appropriate therapies should be discussed in a multidisciplinary team.

Couperus et al. describe the tailored interventional treatment of complex CHD patients suffering from $\mathrm{PH}$ with an impaired pulmonary flow, and emphasised the importance of a multidisciplinary approach [16]. Next to optimal medical PAH-specific therapy, an invasive circulatory adjustment might be necessary to decrease right ventricular overload. Pre-procedural invasive pulmonary haemodynamic measurement (including pulmonary vascular resistance and effective left-to-right shunt quantification) is highly important to evaluate the feasibility of shunt intervention to prevent acute right ventricular failure [17]. Thereafter, each case should be discussed within a multidisciplinary team to reach consensus regarding patient treatment. Therefore, the current guidelines recommend that treatment and follow-up of patients with PAH (and PAH-CHD) should be performed in tertiary centres using a multidisciplinary approach $[1,17]$.

Several aspects of pulmonary hypertension are highlighted in this special issue. These reviews and original articles can further improve our knowledge of $\mathrm{PH}$ and might improve our multidisciplinary care in daily practice.

Open Access This article is distributed under the terms of the Creative Commons Attribution 4.0 International License (http:// creativecommons.org/licenses/by/4.0/), which permits unrestricted use, distribution, and reproduction in any medium, provided you give appropriate credit to the original author(s) and the source, provide a link to the Creative Commons license, and indicate if changes were made.

\section{References}

1. Galiè N, Humbert M, Vachiery J-L, et al. ESC/ERS Guidelines for the diagnosis and treatment of pulmonary hypertension. Eur Heart J. 2015;2016(37):67-119.

2. Simonneau G, Galiè N, Rubin LJ, et al. Clinical classification of pulmonary hypertension. J Am Coll Cardiol. 2004;43(12 Suppl S):5S-12S.

3. Post MC. Association between pulmonary hypertension and an atrial septal defect. Neth Heart J. 2013;21:331-332.

4. Huitema MP, Grutters JC, Rensing BJ, Reesink HJ, Post MC. Pulmonary hypertension complicating pulmonary sarcoidosis. Neth Heart J. 2016. DOI: 10.1007/s12471-016-0847-1

5. Oudiz RJ. Pulmonary hypertension associated with left-sided heart disease. Clin Chest Med. 2007;28:233-241.

6. Peacock AJ, Murphy NF, McMurray JJV, Caballero L, Stewart S. An epidemiological study of pulmonary arterial hypertension. Eur Respir J. 2007;30:104-109.

7. Engelfriet PM, Duffels MGJ, Möller T, et al. Pulmonary arterial hypertension in adults born with a heart septal defect: the Euro Heart Survey on adult congenital heart disease. Heart. 2007;93:682-687.

8. Blok IM, Riel ACMJ van, Schuuring MJ, et al. Decrease in quality of life predicts mortality in adult patients with pulmonary arterial hypertension due to congenital heart disease. Neth Heart J. 2015;23:278-284.

9. Post MC, Mager JJ. Quality of life in pulmonary arterial hypertension. Neth Heart J. 2015;23:275-277.

10. Wapenaar M, Twiss J, Wagenaar M, et al. Adaptation and validation of the Cambridge Pulmonary Hypertension Review (CAMPHOR) for the Netherlands. Neth Heart J. 2016. DOI: 10.1007/s12471016-0849-z.

11. Twiss J, McKenna S, Ganderton L, et al. Psychometric performance of the CAMPHOR and SF-36 in pulmonary hypertension. BMC Pulm Med. 2013;13:45.

12. Baggen V, Driessen M, Post M, et al. Echocardiographic findings associated with mortality or transplant in patients with pulmonary hypertension: A systematic review and meta-analysis. Neth Heart J. 2016. DOI: 10.1007/s12471-016-0845-3.

13. Schölzel BE, Snijder RJ, Mager JJ, et al. Chronic thromboembolic pulmonary hypertension. Neth Heart J. 2014;22:533-541.

14. Riel A van, Schuuring MJ, Hessen ID van, et al. Pulmonary arterial hypertension treatment in congenital heart disease in Singapore versus the Netherlands: age exceeds ethnicity in influencing clinical outcome. Neth Heart J. 2016. DOI: 10.1007/s12471-016-0820$\mathrm{z}$. 
15. Wu W-H, Yang L, Peng F-H, et al. Lower socioeconomic status is associated with worse outcomes in pulmonary arterial hypertension. Am J Respir Crit Care Med. 2013;187:303-310.

16. Couperus L, Henkens I, Jongbloed M, Hazekamp M, Schalij M, Vliegen H. Tailored circulatory intervention in adults with pul- monary hypertension due to congenital heart disease. Neth Heart J. 2016. doi:10.1007/s12471-016-0820-z.

17. Baumgartner H, Bonhoeffer P, Groot NMS De, et al. ESC Guidelines for the management of grown-up congenital heart disease (new version 2010). Eur Heart J. 2010;31:2915-2957. 